\title{
Dysphagia Related Health Consequences among Patients with Acute Stroke in Cairo, Egypt
}

\author{
ASMAA EBRAHIM, M.Sc.*; WARDA Y. MOHAMED, D.N.Sc.*; FOUAD ABD ALLAH, D.N.Sc.** and \\ YOUSSRIA ABD AL-SALAM, D.N.Sc.*
}

The Department of Critical Care and Emergency Nursing, Faculty of Nursing* and The Department of Neurology, Faculty of Medicine**, Cairo University

\begin{abstract}
Background: Dysphagia is a common complication of stroke; it places the patient with acute stroke at risk for poor nutrition and dehydration. In addition to other dangerous complications as post stroke pneumonia.

Aim of Study: To explore dysphagia related health consequences (post stroke pneumonia, length of ICU stay and death) among patients with acute stroke in Cairo, Egypt.

Research Design: A descriptive exploratory research design was utilized.

Research Question: What are the dysphagia related health consequences as indicated by post stroke pneumonia, length of ICU stay and death) among patients with acute stroke in Cairo, Egypt?

Setting: The current study was carried out at a stroke unit affiliated to a selected hospital in Cairo, Egypt.

Sample: A purposive sample consisting of 70 adult male and female patients with acute stroke.

Tools of Data Collection: Three tools were used by the investigator to collect data pertinent to the study: Tool 1: Personal background and medical data, Tool 2: Gugging Swallowing Screen test (GUSS) Tool 3: Post stroke Pneumonia assessment tool.

Results: $30 \%$ of the studied sample was in the age group of $61-70$ years old, $54 \%$ of the study sample was female, and about half $(45.7 \%)$ of the studied sample had a moderate degree of dyaphagia. $37.1 \%$ of the studied sample stayed from 5 to 7 days in the Intensive Care Unit. (7.1\%) of the studied sample had died. More than half $(57.1 \%)$ of the studied sample didn't develop post stroke pneumonia. There was a significant statistical relationship between degree of dysphagia and (post stroke pneumonia, death and length of ICU stay).
\end{abstract}

Conclusion: Dysphagia following the acute stroke is very important issue to be considered during handling, caring and management of patients with it.

Recommendation: Replication of this study on a representative sample for such group of patients all over the Arab

Correspondence to: Dr. Asmaa Ebrahim, E-Mail: Asmaa E2010@yahoo.com
Republic of Egypt is highly recommended to set national protocol for prevention and management of dysphagia related health consequences.

Key Words: Dysphagia - Dysphagia related health consequences - Acute stroke - Patients with acute stroke.

\section{Introduction}

WORLDWIDE, stroke is the second-leading cause of death and the leading cause of adult disability [1], it presents a major global burden to patients, their relatives and whole economies [2], as it is a main cause of functional impairments, with $20 \%$ of survivors requiring institutional care after 3 months and $15 \%$ to $30 \%$ being permanently disabled, therefore it is a life-changing event that affects not only stroke patients themselves but their family members and caregivers as well [3] .

Dysphagia is a common complication of acute stroke [4]. It increases the risk of aspirating food and oral secretions into the lungs and subsequent pneumonia. Post stroke pneumonia risk found to be 3-fold higher in patients with dysphagia compared with those without and 11-fold higher when dysphagia was severe enough to result in aspiration. Pneumonia contributes to longer hospital stays, rehospitalizations, and is an important cause of post stroke mortality [5]

Early identification of dysphagia and aspiration risk by nurses is critical to avoid adverse health consequences for stroke patients. These adverse health consequences include not only aspiration and pneumonia but also dehydration, malnutrition, weight loss, and susceptibility to other illnesses, as well as death. Furthermore, these consequences may lead to reduced patient satisfaction caused by the length of time spent Nil Per Oral (NPO), longer 
length of hospital stay, reduced ability to participate in rehabilitation, and reduced level of independence at discharge [6].

\section{Subjects and Methods}

This study was conducted from October 2016 to July 2017 at the Department four that affiliated to a selected University Hospital in Cairo, Egypt. This Department consisted from two sides Intensive Care Unit with capacity of 16 beds, and intermediate Intensive Care Unit with capacity of 16 beds. A descriptive exploratory research design was utilized in the current study. A purposive sample consisting of 70 adult male and female patients admitted to a selected university hospital in Cairo with acute stroke and willing to participate in this study were included.

\section{Significance of the study:}

More than 750,000 stroke cases occur every year in the United States, making it the fifth leading cause of death and the leading cause of disability. Strokes cost more than $\$ 70$ billion annually, and have a devastating effect on the quality of life of a significant proportion of patients and their caregivers (Khandelwal, Yavagal \& Sacco 2016) [7] In Egypt, according to recent estimates, the overall prevalence rate of stroke is high with a crude prevalence rate of 963/100 000 inhabitants [8] Patients with acute stroke are at risk of developing a wide range of complications such as dysphagia with an incidence rate of 51\%-78\% and aspiration pneumonia with incidences of 13\%-33\% [9]

It has been observed through empirical observation over a period of 3 years in the Intensive Care Units (ICU) that patients with acute stroke are affected to some extent with the post stroke complications such as aspiration pneumonia, dehydration, malnutrition, weight loss, and susceptibility to other illnesses, recurrent hospital admissions as well as death. Furthermore increased length of hospital stay, reduced ability to participate in rehabilitation, and reduced level of independence at discharge.

Therefore, this study will be designed in an attempt to provide health care professionals with an in-depth information about dysphagia following the acute stroke and its related health consequences, which hopefully will be reflected positively on the quality of patients' care and prevent suspected complications. Also this study is expected to raise the nurses' awareness and knowledge regarding dysphagia screening because of its importance for such group of patients to improve their quality of life, decrease post stroke complications, decreases the hospital stay and costs.

\section{Aim of the study:}

The aim of this study was to explore dysphagia related health consequences as indicated by (post stroke pneumonia, length of ICU stay and death) among patients with acute stroke at a university hospital in Cairo, Egypt.

\section{Research question:}

To fulfill the aim of this study the following research question was formulated:

What are dysphagia related health consequences as indicated by post stroke pneumonia, length of ICU stay and death among patients with acute stroke at a university hospital in Cairo, Egypt?

Tools:

Three tools were used by the investigator to collect data pertinent to the study. These tools are:

-Tool 1: Personal background and medical data tool: It covered data related to age, gender, stroke type, stroke severity, (GCS), medical history, date of admission, intake, output, urine color, skin turgor....).

- Tool 2: Gugging Swallowing Screen test (GUSS): It was adopted from (Trapl, et al. 2007) [10], as a bed screening tool for assessing dysphagia. It is divided into two parts: Part 1, Preliminary Assessment (Indirect Swallowing Test): Which is a simple successful saliva swallow and it is the precondition for the second part of the swallowing observation. In which vigilance, voluntary cough, throat clearing, and saliva swallowing are assessed. GUSS part 2: Direct Swallowing Test: The direct swallowing test consists of 3 sequentially performed subtests, starting with semisolid, then liquid, and finally solid textures. Firstly the Semisolid Swallowing Trial, secondly the Liquid Swallowing Trial and finally the Solid Swallowing Trial. The 4 aspiration signs (deglutition, cough, drooling, and voice change) should be assessed carefully during each assessment trial the scoring was as following: Ascore of 20 means no dysphagis and no risk for post stroke aspiration pneumonia, ascore of 15-19 means mild dysphagia with mild risk for post stroke aspiration pneumonia, ascore of 10-14 means moderate dysphagia with moderate risk for post stroke aspiration pneumonia and ascore of 0-9 means severe dysphagia and high risk for post stroke aspiration pneumonia.

- Tool 3: Post Stroke Pneumonia Assessment tool: It was designed to assess the prescence of 
post stroke pneumonia as a health consequence. It contained two catogories which are (A) Clinical findings that include 5 items which are vital signs (body temperature, heart rate and oxygen saturation) and respiratory system assessment (chest sound, purulent respiratory secretions) and (B) Laboratory findings which include 2 items (verified X-ray and Leukocytosis, with a total score of 7, each answer with yes took one degree and the answer with No took 0 . Post stroke pneumonia will be diagnosed by a score from 5 to 7 .

\section{Tool validity and reliability:}

Content validity was done to identify the degree to which the used tools measure what was supposed to be measured. Tools developed by the investigator tool $(1,3)$ were examined by a panel of three medical and critical care nursing experts to determine whether the included items are clear and suitable to achieve the aim of the current study. The Gugging Swallowing Screen tool (2) is a reliable clinical method for detection of dysphagia and aspiration risk in patients with acute stroke. It has been validated against fiberoptic endoscopy, showing sensitivity for GUSS of $100 \%$ and a specificity of $50 \%$ and $69 \%$, when screening was performed respectively by therapists and nurses with an interrator reliability $(\mathrm{k}=0.835, p<0.001)$.

\section{Pilot study:}

A pilot study was carried out on seven patients with acute stroke in the (department four) at a selected university hospital in Cairo to test feasibility, objectivity, and applicability of the data collection tools. Carrying out the pilot study gave the investigator experience to deal with the included subjects, and the data collection tools. Based on results of the pilot study, no modifications were done so; the seven patients of the pilot study were included in the study sample.

\section{Protection of human rights:}

An official permission to conduct the study was obtained from the vice dean of higher education and research-Faculty of Nursing and director of the department four at a selected university hospital in Cairo. Written consents for patients' agreements (or responsible family member's agreement in case of the patient cannot read) to be included in the study were obtained after explanation of the nature and purpose of the study. Each patient/relative was free to either participate or not in the current study and had the right to withdraw from the study at any time without any rational. Also, patients/ relatives were informed that obtained data will not be included in any further researches. Confidenti- ality and anonymity of each subject were assured through coding of all data.

\section{Procedure:}

The current study was conducted on two phases; designing phase and implementation phase. As regards to the designing phase, it involved construction and preparation of different data collection tools, obtaining official agreements to conduct the study, then, it was ended by conduction of the pilot study. After obtaining the official permission to proceed with the proposed study, actual implementation was initiated by obtaining a list of patients who were admitted to the department, with acute stroke, and met the inclusion criteria. Then patients /relatives who agreed to participate in the study were interviewed individually by the investigator to explain the nature and purpose of the study, data collection started from October 2016 to July 2017, and the investigator visited the studied sample in the morning shift to collect the data pertinent to this study.

Written consents were obtained from the patients/relatives, aftrer that dysphagia screening was done using the Gugging Swallowing Screen tool (2), to assess and calulate the degree of dysphagia through the patients response during the test, then repeated regulary with the assessment of care dependancy level to assess the patients' ability to eat and drink. This tool required about 20-30 minutes to be fulfilled.

Then the investigator obtained patients' characteristics, demographic and medical data utilizing tool (1). The investigator used patient's file to obtain some of the needed data such as medical history, stroke severity (NIHSS), stroke location and more over the previous 24-hour data that included; the fluid balance chart, then urine colour, patient's skin turgor and elasticity, blood pressure, quality of heart rate and patient's conscious level all were assessed to identify if there was dehydration or not. This assessment done; on day of admission, after 48 hours from admmission, then repeated weekly till the patient discharged from the ICU. This tool took from the investigator about 10 minutes.

Then the investigator assessed the post stroke pneumonia using the tool (3) on the admission then this assessment repeated after 48 hours from the admission to the patient by the investigator, in each time the investigator assessed the vital signs, oxygen saturation and chest sound. Then the investigator used patient's file to obtain some of the 
needed data regarding patient's laboratory findings: leukocyte count and the chest X-ray report that verify or exclude the post stroke pneumonia, post stroke pneumonia was diagnosed by a score from 5 to 7 . This tool took from the investigator about 10-15 minutes.

\section{Statistical data analysis:}

Upon completion of data collection, data were coded and entered into a computerized data base and analyzed using Statistical Package for Social Sciences (SPSS) program Version (20); then tabulated. Probability level of 0.01 and 0.05 was adopted as the level of significance for all statistical tests done. Descriptive statistics including (A) Frequency and percentage distribution for all variables (B) Mean and standard deviation to describe the central tendency and measure of dispersion for some variables (C) Differential statistics as chisquare was used.

\section{Results}

Socio demographic characteristics of the sample:

Table (1) shows that more than half of the study sample was females and $30 \%$ of them ranged between (61-70) years with a mean age of $59.8 \pm 14.24$, $37 \%$ of the studied sample stayed from 5 to 7 days in the Intensive Care Unit, with a mean length of ICU stay: $12.12 \pm 8.4$.

Table (2) clarifies that approximately half $(47.1 \%)$ of the studied sample had a history of Diabetes Mellitus and Hypertension and approximately three quarter $(71 \%)$ of the studied sample had ischemic stroke. Fig. (1) clarifies that (45.7\%) of the studied sample had a moderate degree of dyaphagia. Fig. (2) illustrates that $58.6 \%$ of the studied sample had a moderate stroke severity.

Results related to answering the research question which states: What are dysphagia related health consequences among patients with acute stroke at a selected hospital in Cairo, Egypt?

As shown from Fig. (3), more than half (57.1\%) of the studied sample didn't develop post stroke pneumonia and Fig. (4) clarifies that only (7.1\%) of the studied sample had died.

Correlation between age, gender and post stroke pneumonia, death occurrence, length of ICU stays:

Table (3) clarifies that there were significant statistical relationships between age and (post stroke pneumonia, length of ICU stay, degree of dysphagia, death).
Correlation between stroke type, stroke location, stroke severity, medical history, degree of dysphagia, post stroke pneumonia, death and length of hospital stay:

Table (4) clarifies that there were significant statistical relationships between degree of dysphagia and (post stroke pneumonia, death and length of ICU stay).

Correlation between lengths of ICU stay, post stroke pneumonia:

Table (5) clarifies that there were significant statistical relationships between length of ICU stay and post stroke pneumonia.

Table (1): Frequency, $(n=70)$. Distribution of the studied sample as regards to age, length of Intensive Care Unit stay and gender.

\begin{tabular}{lll}
\hline & \multicolumn{2}{l}{ Study sample $\mathrm{n}=70$} \\
\cline { 2 - 3 } Variables & \multicolumn{2}{l}{ No. } \\
\hline Age: & 4 & 5.7 \\
$18 \leq 30$ & 5 & 7.1 \\
$>30-\leq 40$ & 13 & 18.6 \\
$>40-\leq 50$ & 14 & 20 \\
$>50-\leq 60$ & 21 & 30 \\
$>60-\leq 70$ & 13 & 18.6 \\
$>70$ & \multicolumn{2}{c}{$59.8 \pm 14.24$} \\
Mean \pm SD & \multicolumn{2}{|}{} \\
Gender: & 32 & $46 \%$ \\
Male & 38 & $54 \%$ \\
Female & \multicolumn{2}{|}{} \\
Length of ICU stay: & 3 & 4.3 \\
Less than 5 days & 26 & 37.1 \\
5-7 & 12 & 17.1 \\
$8-10$ & 12 & 17.1 \\
$11-15$ & 17 & 24.3 \\
More than 15 days & \multicolumn{2}{c}{$12.12 \pm 8.4$} \\
Mean \pm SD & \multicolumn{2}{c}{} \\
\hline
\end{tabular}

Table (2): Frequency distribution of the studied sample as regards to medical history and types of stroke.

\begin{tabular}{lll}
\hline & \multicolumn{2}{l}{ Study sample $\mathrm{n}=70$} \\
\cline { 2 - 3 } Variable & No. & $\%$ \\
\hline Medical history: & & \\
Diabetes & 4 & 5.7 \\
Hypertension & 8 & 11.4 \\
IHD & 2 & 2.9 \\
Nothing & 7 & 10 \\
AF & 3 & 4.3 \\
DM \& HTN & 33 & 47.1 \\
HTN \& IHD & 3 & 4.3 \\
HTN \& AF & 2 & 2.9 \\
DM, HTN \& AF & 2 & 2.9 \\
DM, HTN \& IHD & 6 & 8.6 \\
Stroke type: & & \\
Ischemic stroke & 50 & $29 \%$ \\
Hemorrhagic stroke & 20 & *DM : Diabetes Mellitus. \\
HIHD : Ischemic Heart Disease. & *HTN : Hypertension. \\
*AF : Atrial Fibrillation. & &
\end{tabular}


Table (3): Correlation between age, gender, post stroke pneumonia, death occurrence and length of ICU stay.

\begin{tabular}{cccc}
\hline Variables & $\begin{array}{l}\text { Post stroke } \\
\text { pneumonia }\end{array}$ & $\begin{array}{l}\text { Degree of } \\
\text { dysphagia }\end{array}$ & $\begin{array}{c}\text { Death } \\
\text { occurrence }\end{array}$ \\
\hline $\begin{array}{c}\text { Age: } \\
\chi^{2}\end{array}$ & 20.246 & 0.485 & 0.319 \\
$p$ & $0.001^{*}$ & $0.007^{*}$ & $0.006^{*}$ \\
Gender: & & & \\
$\chi^{2}$ & .406 & 0.582 & 1.435 \\
$p$ & 0.27 & 1.083 & 0.237 \\
\hline
\end{tabular}

**: Correlation is significant at the 0.05 .

Table (4): Correlation between stroke type, stroke location, stroke severity, medical history, degree of dysphagia, and post stroke pneumonia, death and length of hospital stay.

\begin{tabular}{|c|c|c|c|}
\hline Variables & $\begin{array}{l}\text { Post stroke } \\
\text { pneumonia }\end{array}$ & $\begin{array}{l}\text { Length of } \\
\text { ICU stay }\end{array}$ & $\begin{array}{c}\text { Death } \\
\text { occurrence }\end{array}$ \\
\hline $\begin{array}{l}\text { Stroke type: } \\
\chi_{p}^{2}\end{array}$ & $\begin{array}{l}0.053 \\
0.513\end{array}$ & $\begin{array}{l}4.654 \\
0.325\end{array}$ & $\begin{array}{l}2.154 \\
0.175\end{array}$ \\
\hline $\begin{array}{l}\text { Stroke location: } \\
\chi_{p}^{2}\end{array}$ & $\begin{array}{l}7.269 \\
0.29\end{array}$ & $\begin{array}{l}28.841 \\
0.226\end{array}$ & $\begin{array}{l}6.394 \\
0.381\end{array}$ \\
\hline $\begin{array}{l}\text { Stroke severity: } \\
\chi^{2} \\
p\end{array}$ & $\begin{array}{l}4.086 \\
0.13\end{array}$ & $\begin{array}{l}9.714 \\
0.286\end{array}$ & $\begin{array}{l}3.233 \\
0.199\end{array}$ \\
\hline $\begin{array}{l}\text { Medical history: } \\
\chi_{p}^{2}\end{array}$ & $\begin{array}{l}12.257 \\
0.199\end{array}$ & $\begin{array}{l}35.749 \\
0.48\end{array}$ & $\begin{array}{l}3.125 \\
0.959\end{array}$ \\
\hline $\begin{array}{l}\text { Degree of dysphagia: } \\
\chi_{p}^{2}\end{array}$ & $\begin{array}{l}29.316 \\
0.00^{*}\end{array}$ & $\begin{array}{l}35.828 \\
0.000^{*}\end{array}$ & $\begin{array}{l}15.55 \\
0.001 *\end{array}$ \\
\hline
\end{tabular}

**: Correlation is significant at the 0.05 .

Table (5): Correlation between length of ICU stay, post stroke pneumonia.

\begin{tabular}{lc}
\hline Variables & Post stroke pneumonia \\
\hline Length of ICU stay: & \\
$\chi^{2}$ & 47.67 \\
$p$ & $0.001^{*}$ \\
\hline
\end{tabular}

**: Correlation is significant at the 0.05 .

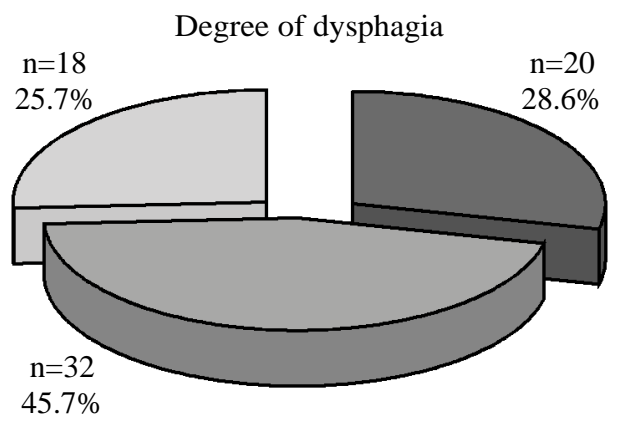

Mild

Moderate

Severe

Fig. (1): Frequency distribution of the studied sample as regards to degree of dysphagia, $(n=70)$.

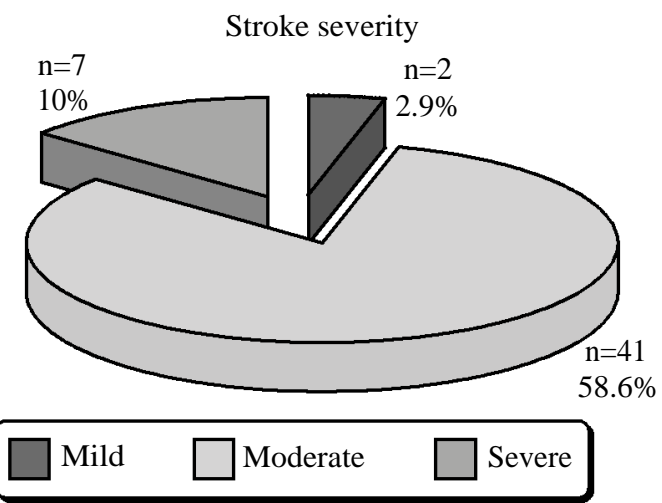

Fig. (2): Percentage distribution of the studied sample as regards to the stroke severity, $(n=70)$.

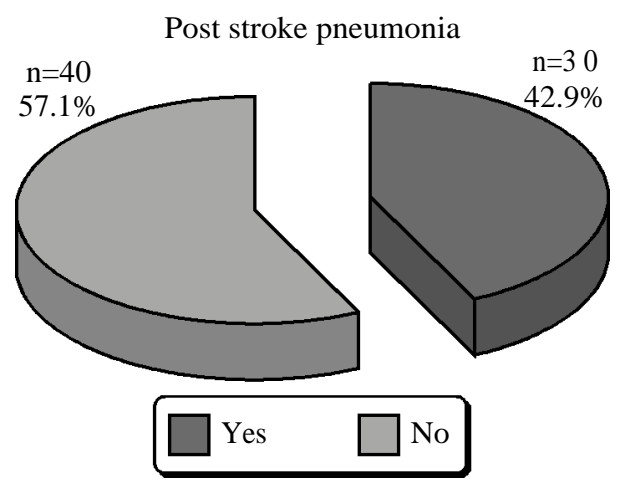

Fig. (3): Percentage distribution of the studied sample as regards post stroke pneumonia, $(n=70)$.

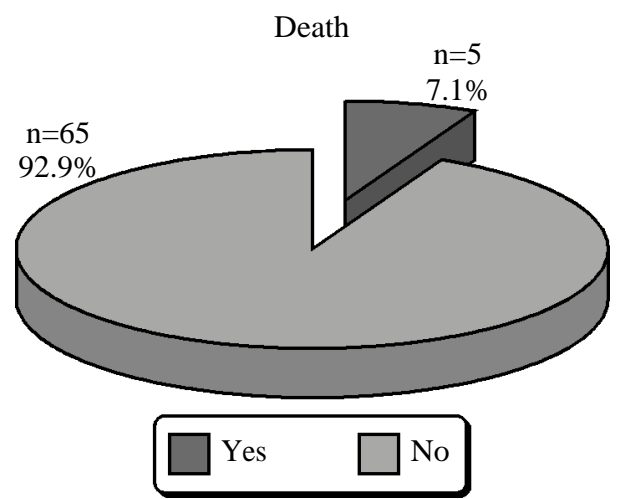

Fig. (4): Frequency distribution of the studied sample as regards to death occurrence, $(n=70)$.

\section{Discussion}

Socio demographic characteristics of the subjects:

The current study revealed that more than half of the studied sample was females. This finding was in agreement with a study done by (Kes, Jura 'Si'c, Zavoreo, Lisak, Jelec \& Matovina, 2016) [11] about age and gender differences in acute stroke hospital patients who found $(53.0 \%)$ were women and (47.0\%) were men. Regards to the age, about one third of the studied sample was ranged between (61-70) with a mean age of: $59.8 \pm 14.24$, this finding was inconsistent with a published study 
done by Arboix, et al., [12] about the association of age and admission mean arterial blood in patients with stroke and found that mean age of participants was $69.8 \pm 13.5$ years, and $\mathrm{Yu}$, et al., [13] found the mean age of the studied sample was $75.65 \pm 11.80$, as well as a study done by (Brogan, Langdon, Brookes, Budgeon \& Blacker 2014) [14] revealed that age of the studied sample was in an average of 71 years with a $(\mathrm{SD}= \pm 14.9)$.

As regards to the medical history, approximately half of the studied sample had a medical history of both Diabetes Mellitus and Hypertension which was in consistent with a published study done by Finlayson, et al., [15] also (Nakajima, et al. 2012) [16] that revealed that more than half of the studied sample had hypertension while about twenty five percent had a diabetes mellitus. Regards to type of stroke in the current study more than two thirds of patients had ischemic stroke and the remaining of patients have hemorrhagic stroke. This finding was in the same line with a published study done by Rohweder, et al. [17] about functional outcome after common post stroke complications occurring in the first 90 days and found a ninety percent had an ischemic stroke and $10 \%$ had a hemorrhagic stroke. As well as a study done by Liu, et al., [18] found that $(75.9 \%)$ patients was with ischemic stroke and $(24.1 \%)$ with hemorrhagic stroke. As regards to the stroke severity more than half of the studied sample had a moderate stroke which was inconsistent with a study done by Svendsen, et al. [19] that revealed that only $17.8 \%$ of the study sample had a moderate stroke severity.

\section{Length of ICU stay:}

As regards to the length of ICU stay the current study revealed that more than one third of the studied sample stayed from 5 to 7 days, with a mean length of ICU stay: $12.12 \pm 8.4$ that was inconsistent with a published study entitled (functional outcome after common post stroke complications occurring in the first 90 days) done by Rohweder, et al., [17] revealed that $2.9 \%$ of the study sample had a mean of ICU stay 5.8, also a study done by Lukasiewicz, et al., [20] showed that the average LOS in the hospital for all patients was $9.8 \pm 9.9$ days. But it was almost consistent with a study entitled (association between pre stroke disability and inpatient mortality and length of acute hospital stay after acute stroke) done by Kwok, et al., [21] and revealed that the overall average LOS was $14.5 \pm 18.8$ days, another study done by (Wu, et al. 2017) [22] found that the mean of ICU stay was 12.2.

\section{Death occurrence:}

The death occurrence was recorded as about seven percent which was almost consistent with a study done by (Brogan, Langdon, Brookes, Budgeon \& Blacker 2014) [14] that recorded a 7.5\% deaths occurred. From the investigator's point of view that result was due to the inclusion criteria of the studied sample which excluded from the study intubated or unconscious patients during the first assessment, patients presented with respiratory aspiration or related complications, such as aspiration pneumonia, pneumonitis, obstructed airways, or pulmonary embolism and those who, at the time of data collection are presenting some clinical lifethreatening conditions as active metastatic cancer, severe liver or kidney failure as well the GCS of patients included in the study was 11-15.

\section{Post stroke pneumonia:}

Post stroke pneumonia occurred in more than one third of the studied sample which was consistent with a study done by (Brogan, Langdon, Brookes, Budgeon \& Blacker 2014) [14] revealed a $52 \%$ of patients had a post stroke pneumonia, while this result was inconsistent with a study done by (Maeshima, Osawa, Hayashi \& Tanahashi (2014) [23] revealed post stroke pneumonia occurred in $17.8 \%$. The investigator refereed that result as it may be due to the caring delivered to the patients, for example, some nursing staff during ryle feeding didn't follow the standards of care regarding nasogastric tube feeding as they, sometimes, missed the patient's position and gave feeding in supine position, also they missed the aspiration of the residual amount and ensuring the tube placement before each feeding all those practices put the patient in the risk for post stroke pneumonia.

In addition to the poor oral care for patients as according to (Sørensen 2013) [9] found that a significant correlation exists between the presence of pathogenic bacteria in the oral cavity and the occurrence of pneumonia as well patients with stroke and dysphagia have an increased risk of aspiration of bacteria, saliva and, thus, for development of pneumonia, and previous studies among other populations have shown a significantly reduced incidence of pneumonia by intensified oral hygiene, in addition to the immobility and the old age all these factors may cause that result regarding post stroke pneumonia in the pertinent study.

Post stroke pneumonia and (age, degree of dysphagia and length of ICU stay):

Post stroke pneumonia in the pertinent study had a significant statistical relationship with age, 
degree of dysphagia and lenghth of ICU stay, this finding was consistent with a finding of large cohort study that was about (the incidence risk of pneumonia within 30 days of stroke, its predisposing factors which done by Bustamante, et al., [24], and a study entitled the impact of pneumonia on a variety of clinical outcomes which done by Maeshima, et al. [23], and they found post stroke pneumonia was associated with lower early and long-term survival, longer hospitalization, and higher disability at discharge, other factors associated with post stroke pneumonia were age, dysphagia, preexistent dependency.

Also a published study done by $\mathrm{Yu}$, et al., [13] revealed that most stroke related pneumonias are believed to result from dysphagia and subsequent aspiration of oropharyngeal material or gastric content. That dysphagia occurs in $37-78 \%$ of stroke patients and increases the risk for pneumonia 3fold and 11-fold in patients with confirmed aspiration: Maeshima, et al. [23] agreed with that result as they found Dysphagia is a main risk factor of stroke associated pneumonia one third of patients with dysphagia develop aspiration pneumonia.

Regarding the association between post stroke pneumonia and length of ICU stay, Maeshima, et al. [23] found that in the absence of stroke associated pneumonia symptoms, more than $50 \%$ of patients with cerebral infarct at the acute phase $(52.1 \%)$ could be discharged from the hospital to home. However, this rate was drastically lower in patients with SAP. This is because patients with Stroke Associated Pneumonia (SAP) could not be weaned from nasogastric and enteral feeding, thus impeding their discharge. For the relation between post stroke pneumonia and age, a published study done by $\mathrm{Yu}$, et al., [13] revealed a similar result that age was significantly higher inpatients suffered from poststroke pneumonia.

Also according to the pertinent study there was a significant statistical relationship between the length of ICU stay and the degree of dysphagia as severity of dysphagia increase the patients' ICU stay, the investigator explained that as patients with moderate or severe dysphagia exposed to different health consequences that contributes to the increases length of ICU stay, also there was study done by Brogan, et al., [24] discussed that Dysphagia may increase length of stay in hospital by $73 \%$, with only $14 \%$ of patients without dysphagia requiring hospitalization longer than 7 days which was consistent with the study's result that revealed a significant statistical relationship between dysphagia and length of ICU stay.
As regards the death occurrence in pertinent study was associated with age, degree of dysphagia that was consistent with Archer, et al., [25] that revealed Dysphagia has been identified as an independent predictor of mortality in stroke and is associated with increased institutionalization and poor outcome. The investigator interpreted that result as dysphagia with its health consequences especially the post stroke pneumonia increase the mortality risk which was reflected in a published study done by $\mathrm{Yu}$, et al., [13] revealed that the rate of mortality within 3 years after stoke onset was significantly higher among patients with poststroke pneumonia.

\section{Conclusion:}

Based on findings of the current study, it can be concluded that dysphagia following the acute stroke is very important issue to be considered during handling, caring and management of such group of patients, that for, according to the pertinent study's results: Degree of dysphagia had a significant relationship with post stroke pneumonia, risk for malnutrition, level of care dependency, dehydration, death and length of ICU stay.

\section{Recommendations:}

Based on findings of the current study, the following are recommended:

- Dysphagia screening should be done by nurses regularly as a routine care.

- Nutritional status of acute stroke patients must be considered in their management and nutritional assessment should be done frequently.

\section{Recommendations for furthers researches:}

- Replication of the study on a larger probability sample selected from different geographical areas in Egypt is recommended to obtain more generalizable data that could be used to establish a national care guide for prevention and management of dysphagia related health consequences.

- Comparative studies could be done between different intensive care units on larger sample using different study tools to validate results.

\section{References}

1- SWAN J., JOURIA Jr. J.M. and KATZ M.J.: Stroke: Comprehensive Acute Stroke Care, 2016.

2- DIRNAGL U.: Found in translation: Preclinical stroke research predicts human pathophysiology, clinical phenotypes and therapeutic outcomes. International Journal of Stroke, 8, 7, 2013.

3- MESCHIA J.F., BUSHNELL C., BODEN-ALBALA B., BRAUN L.T., BRAVATA D.M., CHATURVEDI S. and GOLDSTEIN L.B.: Guidelines for the Primary Prevention 
of Stroke A Statement for Healthcare Professionals From the American Heart Association/American Stroke Association. Stroke, 45 (12); 3754-832, 2014.

4- HANNAWI Y., HANNAWI B., RAO C.P.V., SUAREZ J.I. and BERSHAD E.M.: Stroke-associated pneumonia: Major advances and obstacles. Cerebrovascular Diseases, 35 (5): 430-3, 2013.

5- LAKSHMINARAYAN K., TSAI A.W., TONG X., VAZQUEZ G., PEACOCK J.M., GEORGE M.G. and ANDERSON D.C.: Utility of dysphagia screening results in predicting poststroke pneumonia. Stroke, 41 (12): 284954, 2010.

6- DONOVAN N.J., DANIELS S.K., EDMIASTON J., WEINHARDT J., SUMMERS D. and MITCHELL P.H.: Dysphagia screening: State of the Art Invitational Conference Proceeding From the State-of-the-Art Nursing Symposium, International Stroke Conference 2012, Stroke, 44 (4): e24-e31, 2013.

7- KHANDELWAL P., YAVAGAL D.R. and SACCO R.L.: Acute ischemic stroke intervention. Journal of the American College of Cardiology, 67 (22): 2631-44, 2016.

8- ABD-ALLAH F. and MOUSTAFA R.R.: Burden of stroke in Egypt: Current status and opportunities. International Journal of Stroke, 9 (8): 1105-8, 2014

9- SØRENSEN R.T., RASMUSSEN R.S., OVERGAARD K., LERCHE A., JOHANSEN A.M. and LINDHARDT T.: Dysphagia screening and intensified oral hygiene reduce pneumonia after stroke. Journal of Neuroscience Nursing, 45 (3): 139-46, 2013.

10- TRAPL M., ENDERLE P., NOWOTNY M., TEUSCHL Y., MATZ K., DACHENHAUSEN A. and BRAININ M.: Dysphagia bedside screening for acute-stroke patients The Gugging Swallowing Screen. Stroke, 38 (11): 294852, 2007.

11- KES V.B., JURASI'C M.J., ZAVOREO I., LISAK M., JELEC V. and MATOVINA L.Z.: Age and Gender Differences in Acute Stroke Hospital Patients. Acta clinica Croatica, 55 (1): 69-78, 2016.

12- ARBOIX A., CARTANYÀ A., LOWAK M., GARCÍAEROLES L., PARRA O., OLIVERES M. and MASSONS J.: Gender differences and woman-specific trends in acute stroke: Results from a hospital-based registry (19862009). Clinical neurology and neurosurgery, 127: 19-24, 2014.

13- YU Y.J., WENG W.C., SU F.C., PENG T.I., CHIEN Y.Y., WU C.L. and HUANG W.Y.: Association between pneumonia in acute stroke stage and 3-year mortality in patients with acute first-ever ischemic stroke. Journal of Clinical Neuroscience, 33: 124-12, 2016.

14-BROGAN E., LANGDON C., BROOKES K., BUDGEON C. and BLACKER D.: Respiratory infections in acute stroke: Nasogastric tubes and immobility are stronger predictors than dysphagia. Dysphagia, 29 (3): 340-5, 2014.
15- FINLAYSON O., KAPRAL M., HALL R., ASLLANI E., SELCHEN D. and SAPOSNIK G.: Risk factors, inpatient care, and outcomes of pneumonia after ischemic stroke. Neurology, 77 (14): 1338-45, 2011.

16- NAKAJIMA M., INATOMI Y., YONEHARA T., HASHIMOTO Y., HIRANO T. and UCHINO M.: Oral intake 6 months after acute ischemic stroke. Internal Medicine, 51 (1): 45-50, 2012.

17- ROHWEDER G., ELLEKJÆR H., SALVESEN Ø., NAALSUND E. and INDREDAVIK B. :Functional outcome after common poststroke complications occurring in the first 90 days. Stroke, 46 (1): 65-70, 2015.

18- LIU C.H., LIN S.C., LIN J.R., YANG J.T., CHANG Y.J., CHANG C.H. and LEE T.H.: Dehydration is an independent predictor of discharge outcome and admission cost in acute ischaemic stroke. European Journal of Neurology, 21 (9): 1184-91, 2014.

19- SVENDSEN M.L., EHLERS L.H., HUNDBORG H.H., INGEMAN A. and JOHNSEN S.P.: Processes of early stroke care and hospital costs. International Journal of Stroke, 9 (6): 777-82, 2014

20- LUKASIEWICZ A.M., GRANT R.A., BASQUES B.A., WEBB M.L., SAMUEL A.M. and GRAUER J.N.: Patient factors associated with 30-day morbidity, mortality, and length of stay after surgery for subdural hematoma: A study of the American College of Surgeons National Surgical Quality Improvement Program. Journal of neurosurgery, 124 (3): 760-6, 2016.

21- KWOK C.S., CLARK A., FORD G.A., DURAIRAJ R., DIXIT A.K., DAVIS J. and MYINT P.K.: Association between prestroke disability and inpatient mortality and length of acute hospital stay after acute stroke. Journal of the American Geriatrics Society, 60 (4): 726-32, 2012.

22- WU F.F., HUNG Y.C., TSAI Y.H., YANG J.T., LEE T.H., LIOW C.W. and LIN L.C.: The influence of dehydration on the prognosis of acute ischemic stroke for patients treated with tissue plasminogen activator. B.M.C. cardiovascular disorders, 17 (1): 154, 2017.

23- MAESHIMA S., OSAWA A., HAYASHI T. and TANAHASHI N.: Elderly age, bilateral lesions, and severe neurological deficit are correlated with stroke-associated pneumonia. Journal of Stroke and Cerebrovascular Diseases, 23 (3): 484-9, 2014

24- BUSTAMANTE A., GARCÍA-BERROCOSO T., RODRIGUEZ N., LLOMBART V., RIBÓ M., MOLINA C. and MONTANER J.: Ischemic stroke outcome: A review of the influence of post-stroke complications within the different scenarios of stroke care. European Journal of Internal Medicine, 29: 9-21, 2016.

25- ARCHER S.K., WELLWOOD I., SMITH C.H. and NEWHAM D.J.: Dysphagia therapy in stroke: A survey of speech and language therapists. International journal of language \& communication disorders, 48 (3): 283-96, 2013. 


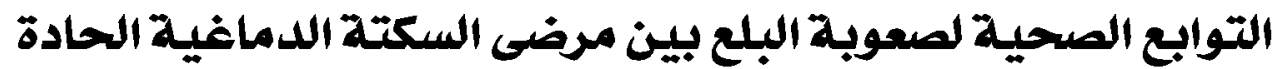

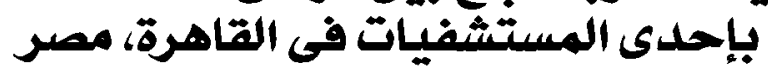

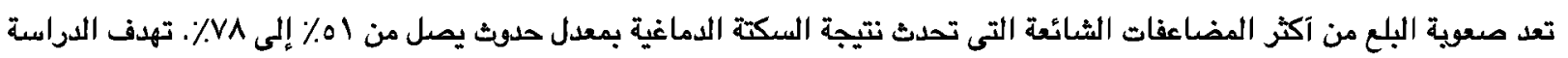

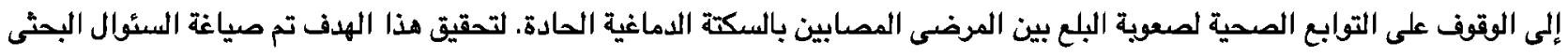

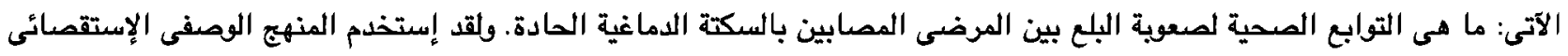

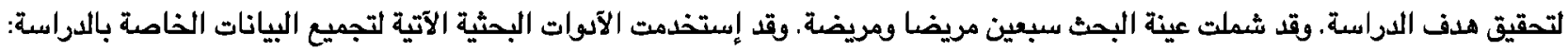

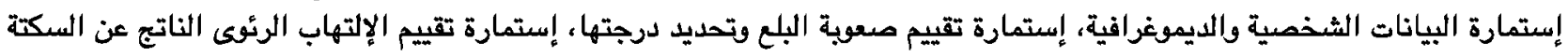

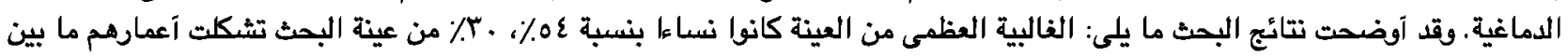

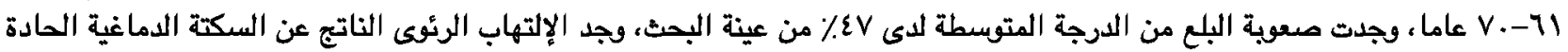

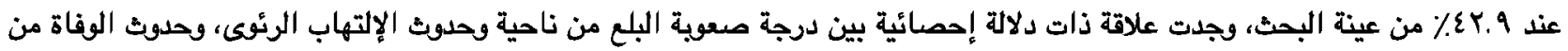

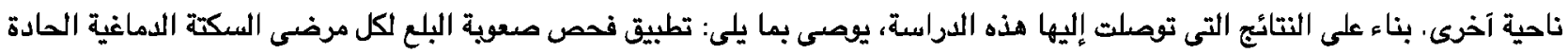

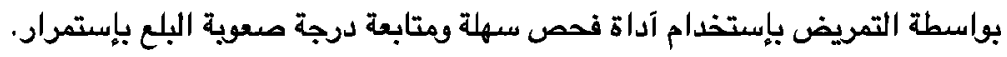

